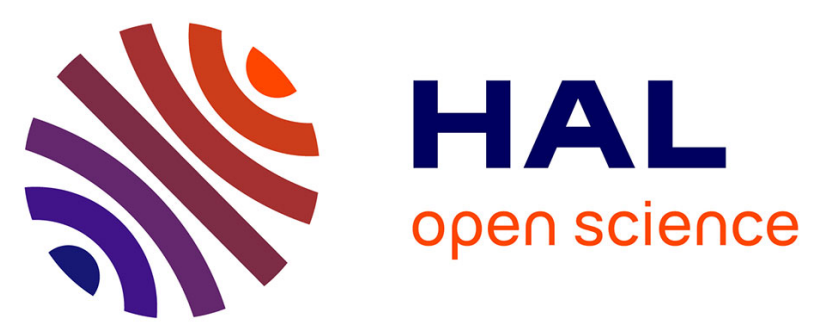

\title{
Structural influence of antibody recruiting glycodendrimers (ARGs) on antitumoral cytotoxicity
}

Biagio Todaro, Silvia Achilli, Benjamin Liet, Eugénie Laigre, Claire Tiertant, David Goyard, Nathalie Berthet, Olivier Renaudet

\section{- To cite this version:}

Biagio Todaro, Silvia Achilli, Benjamin Liet, Eugénie Laigre, Claire Tiertant, et al.. Structural influence of antibody recruiting glycodendrimers (ARGs) on antitumoral cytotoxicity. Biomaterials Science, 2021, 9 (11), pp.4076 - 4085. 10.1039/d1bm00485a . hal-03325147

\section{HAL Id: hal-03325147 https://hal.science/hal-03325147}

Submitted on 24 Aug 2021

HAL is a multi-disciplinary open access archive for the deposit and dissemination of scientific research documents, whether they are published or not. The documents may come from teaching and research institutions in France or abroad, or from public or private research centers.
L'archive ouverte pluridisciplinaire HAL, est destinée au dépôt et à la diffusion de documents scientifiques de niveau recherche, publiés ou non, émanant des établissements d'enseignement et de recherche français ou étrangers, des laboratoires publics ou privés. 


\section{Structural influence of Antibody Recruiting Glycodendrimers \\ (ARGs) on antitumoral cytotoxicity}

Biagio Todaro, $\ddagger^{\mathrm{a}}$ Silvia Achilli, $\ddagger^{\mathrm{a}}$ Benjamin Liet, ${ }^{\mathrm{a}}$ Eugénie Laigre, ${ }^{\mathrm{a}}$ Claire Tiertant, ${ }^{\mathrm{a}}$ David Goyard, ${ }^{a}$ Nathalie Berthet ${ }^{\star a}$ and Olivier Renaudet ${ }^{\star a}$

a Univ. Grenoble Alpes, CNRS, DCM UMR 5250, F-38000 Grenoble, France

‡ These authors contributed equally to this work

${ }^{*}$ Corresponding authors: $\quad$ nathalie.berthet@univ-grenoble-alpes.fr;

olivier.renaudet@univ-grenoble-alpes.fr 


\section{Abstract}

The recruitment of endogenous antibodies against cancer cells has become a reliable antitumoral immunotherapeutic alternative over the last decade. The covalent attachment of antibody and tumor binding modules (ABM and TBM) within a single, well-defined synthetic molecule was indeed demonstrated to promote the formation of an interacting ternary complex between both the antibodies and the targeted cell, which usually results in the simultaneous immune-mediated cellular destruction. In a preliminary study, we have described the first Antibody Recruiting Glycodendrimers (ARGs), combining cRGD as ligands for the avß3-expressing melanoma cell line M21 and Rha as ligand for natural $\lg \mathrm{M}$, and demonstrated that multivalency is an essential requirement to form this complex. In the present study, we synthesized a new series of ARGs composed of ABMs, i.e. self-condensed rhamnosylated cyclopeptide and polylysine dendrimer, which have been conjugated to the TBM with or without spacer. Flow cytometry and confocal microscopy experiments with human serum and different cell lines revealed that the ABM geometry significantly influences the ternary complex formation in M21, whereas no significant binding occurs in BT 549 having low integrin expression. In addition, we demonstrate with a cellular viability assay that ARGs induce high level of cytotoxicity against M21 which is also in close correlation with the ABM structure. In particular, we have shown that ARG combining cyclopeptide core and branches, with or without spacer, induce $40-57 \%$ of selective cytotoxicity against M21 cells in the presence of human serum as the unique source of immunity effectors. Finally, we also highlight that the spacer between ABM and TBM enables an increase of the immune-mediate cytotoxicity even with ABM of lower valency. 


\section{Introduction}

Immunotherapy represents a promising strategy to fight against various diseases such as infections and cancer..$^{1,2,3}$ Besides biotechnological approaches that still suffer from technical difficulties and cost of production, fully synthetic molecules have been proved as credible alternatives over the last years. ${ }^{4}$ In particular, Antibody Recruiting Molecules (ARMs) composed of two binding modules, one for natural antibodies present in the blood stream of humans (e.g. dinitrophenol, peptide, $\alpha-G a l$ or L-Rha) and the other for pathogens or cancer cells (e.g. receptor ligand, enzyme inhibitor), can stimulate immune-mediated cytotoxicity against the biological target.5,6,7 More recently, elegant studies have demonstrated that Antibody Recruiting Polymers $(\mathrm{ARPs})^{8}$ displaying multiple copies of dinitrophenol (DNP) as the antibody-binding motif can be attached to cancer cell surface by lipid insertion ${ }^{9}$ or by a labelling approach combining metabolic engineering and click chemistry. ${ }^{10}$ The resulting construction was found to recruit commercial anti-DNP antibodies at the cancer cell surface and to induce antibody-mediated killing by macrophages. Following the Ab-drug conjugate concept, $\alpha$-Gal was alternatively conjugated to tumor-specific Abs to take advantage of the natural abundance of anti-a-Gal Abs in humans. ${ }^{11}$ The introduction of $\alpha-G a l$ either as a single ligand or as a dendrimeric structure was shown to significantly increase the cellular cytotoxicity in the presence of human serum and after addition of rabbit complement.

We recently identified one molecule composed of two antibody and tumor binding modules (ie ABM and TBM) consisting in a hexadecavalent dendrimer of Rha and a tetravalent cluster of $c R G D$ as an $\alpha \vee \beta_{3}$ integrin ligand. After covalent conjugation of these modules by click chemistry, the resulting supramolecular construct, namely 
Antibody Recruiting Glycodendrimer (ARG), was shown to form a ternary complex between natural IgM present in the human serum and melanoma M21 cancer cell without pre-immunization, thus suggesting its ability to stimulate of antitumoral cytotoxicity. ${ }^{5}$ In agreement with other groups, we also demonstrated the importance of multiple presentation of ligands for the interaction with both natural antibodies and tumor receptors. ${ }^{8,12}$ If multivalency is a key phenomenon in biological processes involving carbohydrate binding proteins (CBPs), ${ }^{13,14,15}$ multivalent interactions induced by synthetic ligands with circulating antibodies was only reported in rare cases, presumable due to the large variety of isotypes in the human population. ${ }^{16,17}$ Given the importance of structural parameters in this field, we studied herein the impact of 1) the ABM geometry and 2) the spacer between ABM and TBM on the ternary complex formation. More importantly, we confirmed that ARGs with suitable geometry and linker can activate a strong immune-mediated cytotoxicity against cancer cells having high integrin expression in presence of human serum as the unique source of immunity effectors. The cytotoxic activity was indeed found to depend on the ARG structure and to have similar level with serum of different human donors.

\section{Experimental}

\section{General methods}

All chemical reagents were purchased from Aldrich (Saint Quentin Fallavier, France) or Acros (Noisy-Le-Grand, France) and were used without further purification. All protected amino acids and Fmoc-Gly-Sasrin®resin was obtained from Advanced ChemTech Europe (Brussels, Belgium), Bachem Biochimie SARL (Voisins-Les- 
Bretonneux, France) and France Biochem S.A. (Meudon, France). For peptides and glycopeptides, analytical RP-HPLC was performed on a Waters alliance 2695 separation module, equipped with a Waters 2489 UV/visible detector. Analyses were carried out at $1.23 \mathrm{~mL} / \mathrm{min}$ (Interchim UPTISPHERE XSERIE, $\mathrm{C}_{18}, 5 \mu \mathrm{m}, 125 \times 3.0 \mathrm{~mm}$ ) with UV monitoring at $214 \mathrm{~nm}$ and $250 \mathrm{~nm}$ using a linear A-B gradient (buffer A: 0.09\% $\mathrm{CF}_{3} \mathrm{CO}_{2} \mathrm{H}$ in water; buffer $\mathrm{B}: 0.09 \% \mathrm{CF}_{3} \mathrm{CO}_{2} \mathrm{H}$ in $90 \%$ acetonitrile). Preparative HPLC was performed on Gilson GX 281 equipped with a fraction collector or on Waters equipment consisting of a Waters 600 controller and a Waters 2487 Dual Absorbance Detector. Purifications were carried out at $22.0 \mathrm{~mL} / \mathrm{min}$ (VP 250x21 mm nucleosil 100$7 \mathrm{C}_{18}$ ) with UV monitoring at $214 \mathrm{~nm}$ and $250 \mathrm{~nm}$ using a linear $\mathrm{A}-\mathrm{B}$ gradient. ${ }^{1} \mathrm{H}$ spectra were recorded on BrukerAvance III $500 \mathrm{MHz}$ spectrometers and chemical shifts $(\delta)$ were reported in parts per million $(\mathrm{ppm})$. Spectra were referenced to the residual proton solvent peaks relative to the signal of $\mathrm{D}_{2} \mathrm{O}\left(4.79 \mathrm{ppm}\right.$ for $\left.{ }^{1} \mathrm{H}\right)$. ESI mass spectra of peptides and glycopeptides were measured on an Esquire 3000 spectrometer from Bruker. MALDI-ToF were performed on an AutoFlex I Bruker after sample pretreatment in an OligoR3 microcolumn (Applied Biosystems, USA) using 2,5dihydroxybenzoic acid matrix. HRMS analyses were performed on a Waters Xevo $^{\circledR}$ G2-S QTof at Mass Spectrometry facility, PCN-ICMG, Grenoble.

\section{Synthetic procedures}

General procedure $\boldsymbol{A}$ for the preparation of glycoclusters by CuAAC

Propargyl glycoside or alkyne-substituted glycocluster (4.4 eq.) and azidefunctionalized scaffold (1 eq.) were dissolved in $1 \mathrm{~mL}$ of a 1:1 mixture of DMF and PBS buffer ( $\mathrm{pH}$ 7.5). A solution of $\mathrm{CuSO}_{4} \cdot 5 \mathrm{H}_{2} \mathrm{O}$ (0.5 eq.) and THPTA (1 eq.) in PBS was added to a solution of sodium ascorbate ( 3 eq.) in PBS. This mixture was added to the 
solution containing the azide and alkyne which was degassed with argon and stirred at r.t. for 2 hours after which RP-HPLC showed completion of the reaction. Chelex ${ }^{\circledR}$ resin was then added to the reaction mixture which was stirred for 45 minutes. The resin was filtered off, rinsed with water and the filtrate purified by semi-preparative RPHPLC. Fractions containing the product were combined and lyophilized.

General procedure $\boldsymbol{B}$ for the preparation of peptidoclusters by CuAAC Alkyne-substituted peptide (4.6 eq.) and azide-functionalized scaffold (1 eq.) were dissolved in $1 \mathrm{~mL}$ of DMF ( $\mathrm{pH}$ 7.5). A solution of $\mathrm{CuSO}_{4} \cdot 5 \mathrm{H}_{2} \mathrm{O}$ (0.5 eq.) and THPTA (1 eq.) in PBS was added to a solution of sodium ascorbate (3 eq.) in PBS. This mixture was added to the solution containing the azide and alkyne which was degassed with argon and stirred at r.t. for 2 hours after which RP-HPLC showed completion of the reaction. Chelex ${ }^{\circledast}$ resin was then added to the reaction mixture which was stirred for 45 minutes. The resin was filtered off, rinsed with water and the filtrate purified by semipreparative RP-HPLC. Fractions containing the product were combined and lyophilized.

General procedure $\boldsymbol{C}$ for the introduction of alkyne and azide on the free lysine residue of multivalent constructions

Tetra- or hexadecavalent compound (1 eq.) was dissolved in dry DMF (1 mL), DIPEA was added to reach $\mathrm{pH} \sim 9-10$ (c.a. $20 \mu \mathrm{L}$ ) then succinimide ester of pentynoic or azidoacetic acid (1.5 eq.) was added. The reaction mixture was stirred at r.t. for 1 hour after which RP-HPLC showed completion of the reaction. The mixture was diluted with water $(3 \mathrm{~mL})$ and purified by semi-preparative RP-HPLC. Fractions containing the product were combined and lyophilized. 
General procedure $\boldsymbol{D}$ for the introduction of PEG-azide on the free lysine residue of multivalent constructions

Tetra- or hexadecavalent compound (1 eq.) was dissolved in dry DMF (1 mL), DIPEA was added to reach $\mathrm{pH} \sim 9-10$ (c.a. $20 \mu \mathrm{L}$ ) then 2-[2-(2-Azidoethoxy)ethoxy]-acetic acid potassium salt (2 eq.) and PyBOP (2 eq) were added. The reaction mixture was stirred at r.t. for 1 hour after which RP-HPLC showed completion of the reaction. The mixture was diluted with water $(3 \mathrm{~mL})$ and purified by semi-preparative RP-HPLC. Fractions containing the product were combined and lyophilized.

General procedure $\boldsymbol{E}$ for the preparation of ARM's by CuAAC Azido-functionalized ABM (1eq.) and alkyne-functionalized TBM (1 eq.) were solubilized in $1 \mathrm{~mL}$ of a 1:1 mixture of DMF and PBS buffer ( $\mathrm{pH}$ 7.5). A solution of $\mathrm{CuSO}_{4} \cdot 5 \mathrm{H}_{2} \mathrm{O}$ (0.2 eq.) and THPTA (0.4 eq.) in PBS was added to a solution of sodium ascorbate (1 eq.) in PBS. This mixture was added to the solution containing the azide and alkyne which was degassed with argon and stirred at r.t. for 2 hours after which RP-HPLC showed completion of the reaction. Chelex® resin was then added to the reaction mixture which was stirred for 45 minutes. The resin was filtered off, rinsed with water and the filtrate purified by semi-preparative RP-HPLC. Fractions containing the product were combined and lyophilized.

\section{Cell culture method}

Human M21 melanoma cell line (gift from J.L. Coll, IAB laboratory, Grenoble) was grown in Dulbecco's modified eagle medium (DMEM, Sigma) supplemented with 10\% (v/v) of fetal bovine serum (Sigma), $100 \mu \mathrm{g} / \mathrm{mL}$ streptomycin and $100 \mathrm{U} / \mathrm{mL}$ penicillin 
(Sigma). BT-549 cells obtained from ATCC were cultured according to the supplier's instructions. All cells were maintained at $37^{\circ} \mathrm{C}$ in a $5 \% \mathrm{CO}_{2}$ humidified atmosphere.

\section{Flow cytometry and confocal microscopy}

\section{Expression of cell-surface integrin $\alpha_{\vee} \beta_{3}$}

Near confluent cells were detached with trypsin-EDTA (Sigma), then resuspended and diluted to $1 \times 10^{6}$ cells $/ \mathrm{mL}$ in HBSS (Hank's Balanced Salt Solution with calcium and magnesium, Sigma) before to be fixed with $4 \%$ paraformaldehyde (PFA) for $10 \mathrm{~min}$ at $37^{\circ} \mathrm{C}$. After two washes with HBSS, cells were incubated with an anti-CD51/CD61 conjugated phycoerythrin (PE) antibody (BD Pharmingen ${ }^{\mathrm{TM}}$ ) (diluted at 1/500 in HBSS) during $1 \mathrm{~h}$ at room temperature. Cells were then washed 1 time with PBS and resuspended in $1 \mathrm{~mL}$ of HBSS and immediately analyzed by flow cytometry (BD LSR FORTESSA, laser excitation at $\lambda=488 \mathrm{~nm}$, emission bypass filter at $575 / 26$ ).

\section{Recruiting assay of anti-Rha antibody form human serum}

Cells $\left(1 \times 10^{6}\right.$ cells $/ \mathrm{mL}$ in HBSS) were fixed with PFA (as described previously) then incubated with ARGs (100 nM in HBSS) during $1 \mathrm{~h}$ at room temperature. After one wash with HBSS, cells were incubated with human serum (HS, 50\% in HBSS) obtained from a healthy human male donor (Sigma-Aldrich or the Etablissement Français du Sang, EFS Grenoble) for $2 \mathrm{~h}$ at room temperature. After one wash with HBSS, the antiRha antibody binding was finally revealed by adding an Alexa-Fluor488-coupled antihuman IgM secondary antibody (1:400, Fisher Scientific). After $1 \mathrm{~h}$ of incubation at room temperature then washing (HBSS), cells were immediately analyzed for the Alexa-Fluor488 intensity with a flow cytometer (BD LSR FORTESSA, laser excitation 
at $\lambda=488 \mathrm{~nm}$, emission bypass filter at 525/50) and a confocal microscope (TCS SP8 CSU, Leica, laser excitation at $\lambda=448 \mathrm{~nm}$ and fluorescence emission collected between $\lambda=495$ and $545 \mathrm{~nm})$.

\section{Cell viability assay}

U-shaped 96-well microtiter plates were treated with $200 \mu \mathrm{L}$ of "blocking buffer" (25 $\mathrm{mM} \mathrm{Na} \mathrm{CO}_{3}, \mathrm{pH} 9.6, \mathrm{BSA}(1.5 \% \mathrm{w} / \mathrm{v})$, and Tween-20 (0.5\% w/v, Sigma) for $2 \mathrm{~h}$ at room temperature. Confluent cultures of cells were detached as described previously, washed, counted, and resuspended at $1.25 \times 10^{6} \mathrm{cells} / \mathrm{mL}$ in PBS. Cells were fluorescently labelled with BCECF-AM (2',7'-Bis-(2',7'-Bis(2-carboxyethyl)-5(6)carboxyfluorescein acetoxymethyl ester, $2 \mu \mathrm{g} / \mathrm{mL}$, Sigma) for 30 min at $37^{\circ} \mathrm{C}$, washed and diluted to $4 \times 10^{5}$ cells $/ \mathrm{mL}$ for activation in HBSS enriched with BSA $(1.5 \% \mathrm{w} / \mathrm{v})$. After $60 \mathrm{~min}$ on ice, $1 \times 10^{4}$ cells/well were added to the rinsed wells and, after centrifugation and removal of supernatant, $100 \mu \mathrm{L}$ ARM (100 nM) was added. Incubation occurred at room temperature for $1 \mathrm{~h}$, followed by washing step. Cells were then incubated with human serum (HS, 50\% in HBSS), $2 \mathrm{~h}$ at room temperature. The maximum cell lysis (max) was obtained by treating cells with the non-ionic detergent TRITON ( $1 \%(\mathrm{w} / \mathrm{v})$ final concentration) for $1 \mathrm{~h} 30$ at $37^{\circ} \mathrm{C}$. After a final centrifugation, the supernatant was transferred to fluo COSTAR Assay plate and the fluorescent signal was read on an POLARstar Omega plate reader (BMG labtech). The spontaneous release of fluorescence (BG,background) was determined without any $A R G$ addition. Cytotoxicity was calculated by the following equation:

$\%$ cytotoxicity $=[($ sample $-B G) /(\max -B G)] \times 100$ 


\section{Results and Discussion}

\section{Synthesis of ARGs}

Multivalency is a key concept which controls a large panel of biological processes by promoting strong and selective interactions between receptors and ligands. ${ }^{13-15}$ Among them, carbohydrates bind to proteins such as lectins and antibodies through complex mechanisms whose efficiency is closely dependent on the structural features of the interacting partners. Therefore, we anticipated that the geometry of ABMs could significantly influence the binding affinity with serum antibodies specific for L-Rha. ${ }^{16,17}$ To confirm this hypothesis, we synthesized a series of rhamnosylated scaffolds based on cyclopeptide (C) and polylysine dendrimer (D) cores that were self-condensed to provide hexadecavalent structures with various structural features (Fig. 1). 18,19,20,21

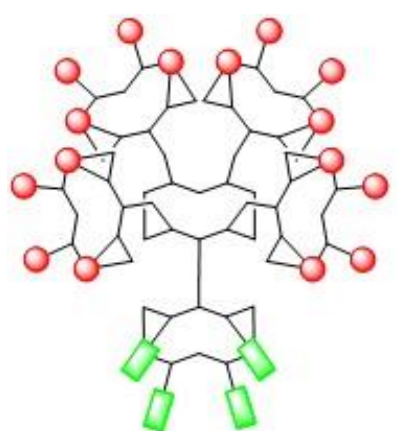

$16 \mathrm{CC}$

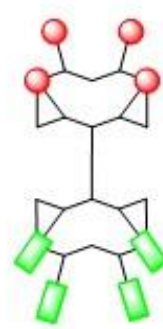

$4 \mathrm{C}$

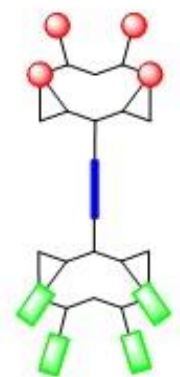

$4 C-P$

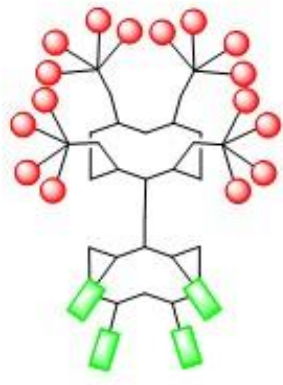

16CD

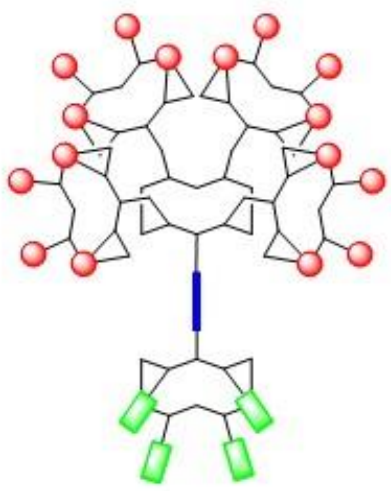

16CC-P

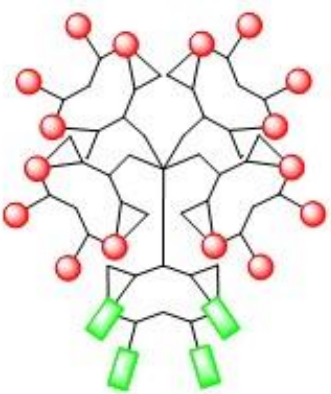

16DC

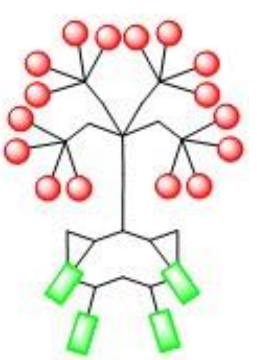

16DD 
Fig. 1 Schematic representation of ARGs. Abbreviations: 16CC: 16 Rha units displayed on a cyclopeptide core (C) and 4 cyclopeptides (C) at the periphery; 16CD: 16 Rha units displayed on a cyclopeptide core (C) and 4 dendrimers (D) at the periphery; 16DC: 16 Rha units displayed on a dendrimer core (D) and 4 cyclopeptides (C) at the periphery; 16DD: 16 Rha units displayed on a dendrimer core (D) and 4 dendrimers (D) at the periphery; 4C: 4 Rha units displayed on a cyclopeptide core (C); 4C-P: 4 Rha units displayed on a cyclopeptide core (C) and having a PEG spacer (P) between ABM and TBM; 16CC-P: 16 Rha units displayed on a cyclopeptide core (C) and 4 cyclopeptides (C) at the periphery and having a PEG spacer (P) between ABM and TBM.

For this purpose, we followed the synthetic route described previously with lectins (Scheme 1), ${ }^{12}$ which consists in the functionalization of the tetravalent azido cyclopeptide $\mathbf{1}$ and dendron 2 with propargylated cRGD and $\alpha$-L-Rha by coppercatalysed azide-alkyne cycloaddition (CuAAC). The free lysine of the resulting compounds 3-5 was next conjugated by amide coupling with an activated ester of linker bearing either an azide (6-7), an alkyne (8-10) or a PEGylated azide (11).

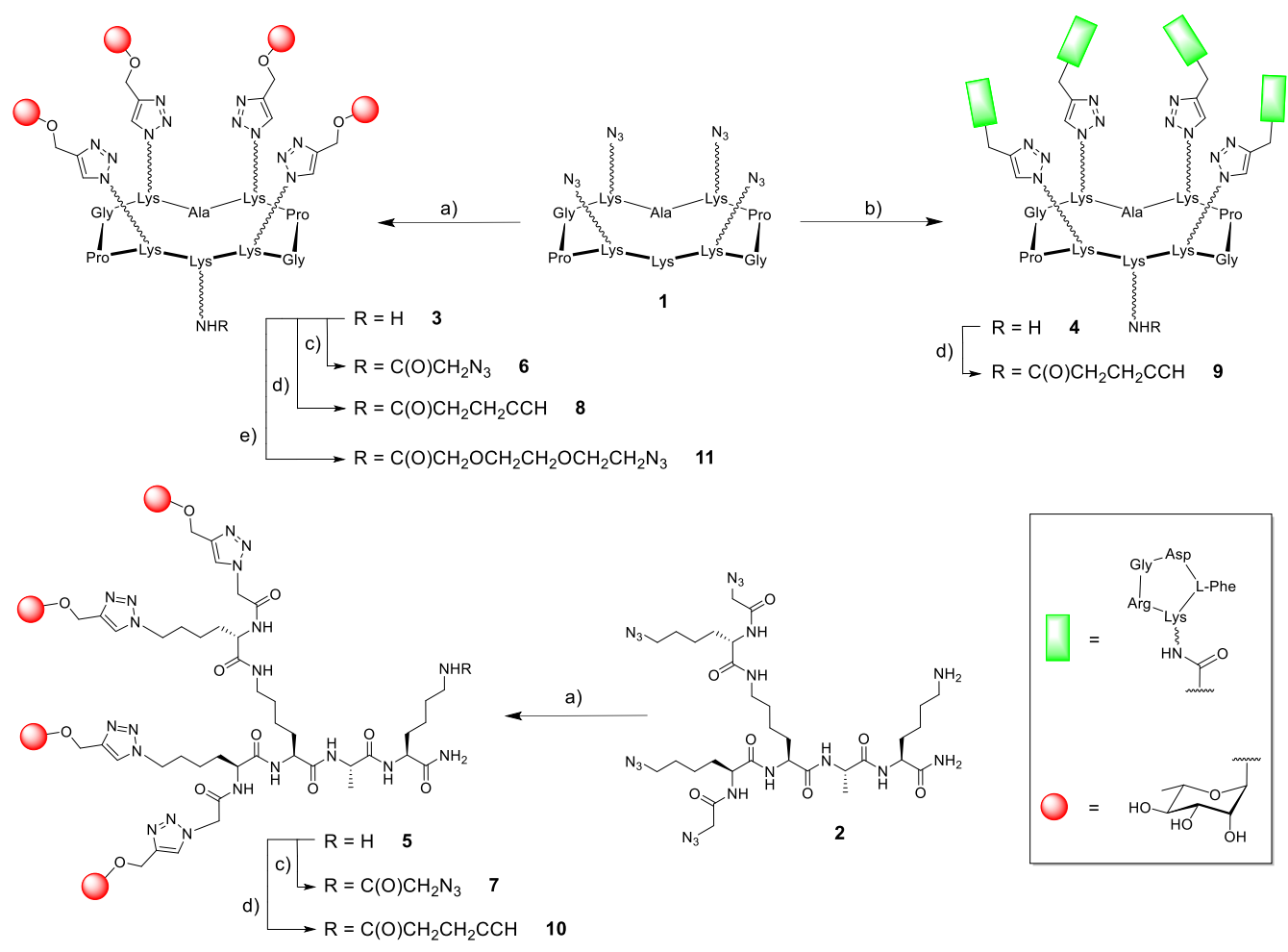

Scheme 1. Synthesis of tetravalent conjugates (ABM in red, TBM in green). Reagents and conditions: a) Propargyl a-L-rhamnopyranoside, CuSO $4 \cdot 5 \mathrm{H}_{2} \mathrm{O}$, THPTA, Na ascorbate, DMF, PBS, rt, 1h; b) cRGDpentynoic acid, $\mathrm{CuSO}_{4} \cdot 5 \mathrm{H}_{2} \mathrm{O}$, THPTA, Na ascorbate, DMF, PBS, rt, 2h; c) Azidoacetic acid succinimide ester, DIPEA, DMF, rt, 1h; d) Pentynoic acid succinimide ester, DIPEA, DMF, rt, 1h; e) 2-[2-(2Azidoethoxy)ethoxy]-acetic acid potassium salt, PyBOP, DIPEA, DMF, rt, $1 \mathrm{~h}$. 
Hexadecavalent ABMs 12-15 were next assembled in different combination from compounds 8 and 10 (Scheme 2). These reactions were performed at room temperature with copper sulfate in the presence of tris(3-hydroxypropyltriazolylmethyl)amine (THPTA) and sodium ascorbate in a mixture of DMF and PBS (pH 7.4). Typically, each reaction was completed within $1-2$ hours as confirmed by analytical RP-HPLC. After semi-preparative RP-HPLC purification, all the compounds were functionalized with the short or PEGylated azide linkers by amide coupling to provide a series of hexadecavalent ABMs 16-19 and 20, respectively.
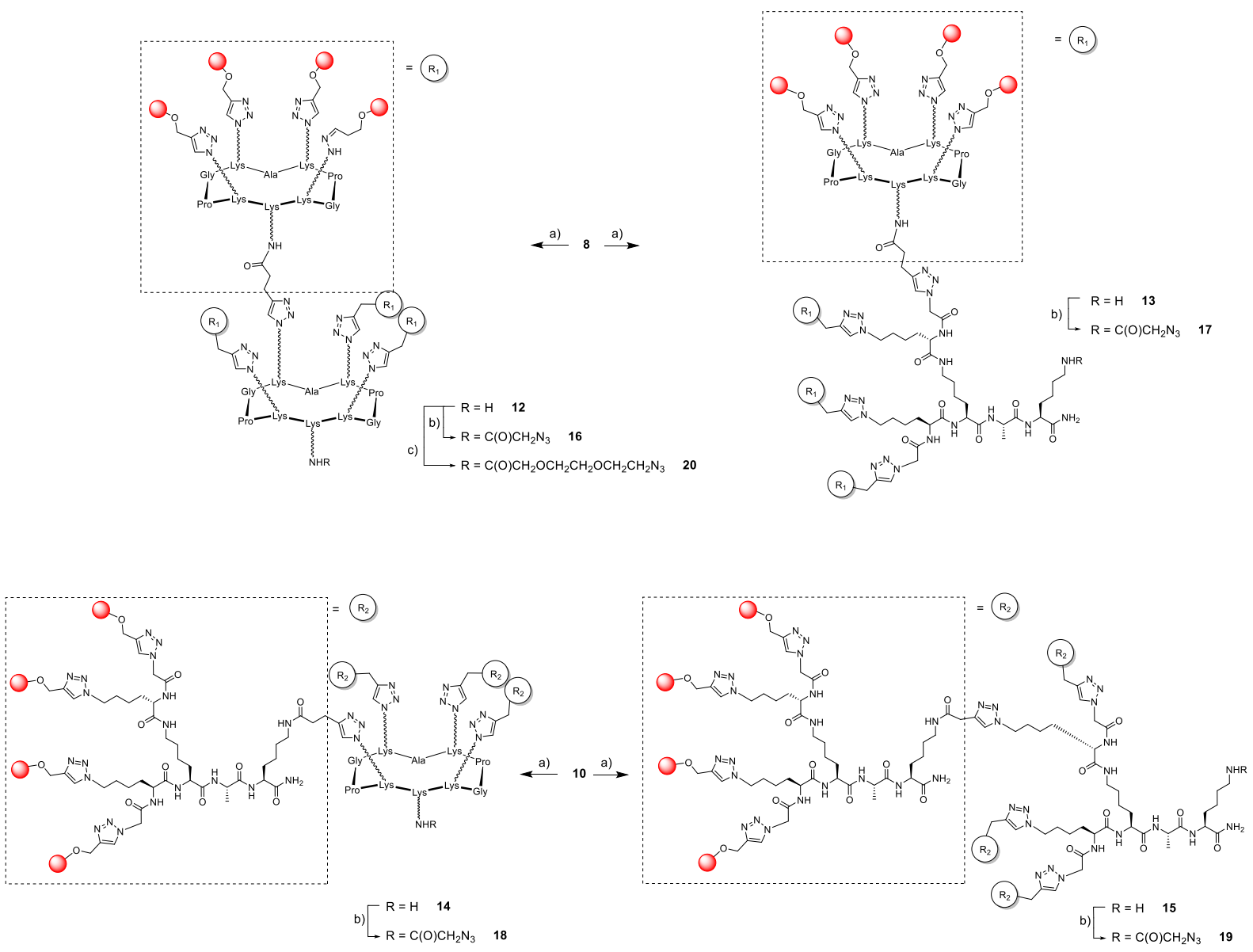

Scheme 2. Synthesis of hexadecavalent ABMs. Reagents and conditions: a) $\mathbf{1}$ (for $\mathbf{1 2}$ and 14) or $\mathbf{2}$ (for 13 and 15), $\mathrm{CuSO}_{4} \cdot 5 \mathrm{H}_{2} \mathrm{O}$, THPTA, Na ascorbate, DMF, PBS, rt, $1 \mathrm{~h}$; b) Azidoacetic acid succinimide ester, DIPEA, DMF, rt, 1h; c) 2-[2-(2-Azidoethoxy)ethoxy]-acetic acid potassium salt, PyBOP, DIPEA, DMF, rt, $1 \mathrm{~h}$. 
Finally, five different ARGs varying in the valency and the orientation of Rha (16CC, 16CD, 16DC, 16DD and 4C) and two structures having PEGylated spacer between ABM and TBM (4C-P and 16CC-P) were synthesized (Scheme 3). Given its high efficiency, CuAAC was repeated to conjugate ABMs and TBMs which is the most critical step of the ARG assembly. The coupling reactions were performed in the conditions described above and no significant difference of reactivity was observed despite the structural complexity of ARGs. Each compound was thus obtained in 56$87 \%$ yield after semi-preparative RP-HPLC purification and characterized by HR-MS and NMR (See ESI) before the biological evaluation. 


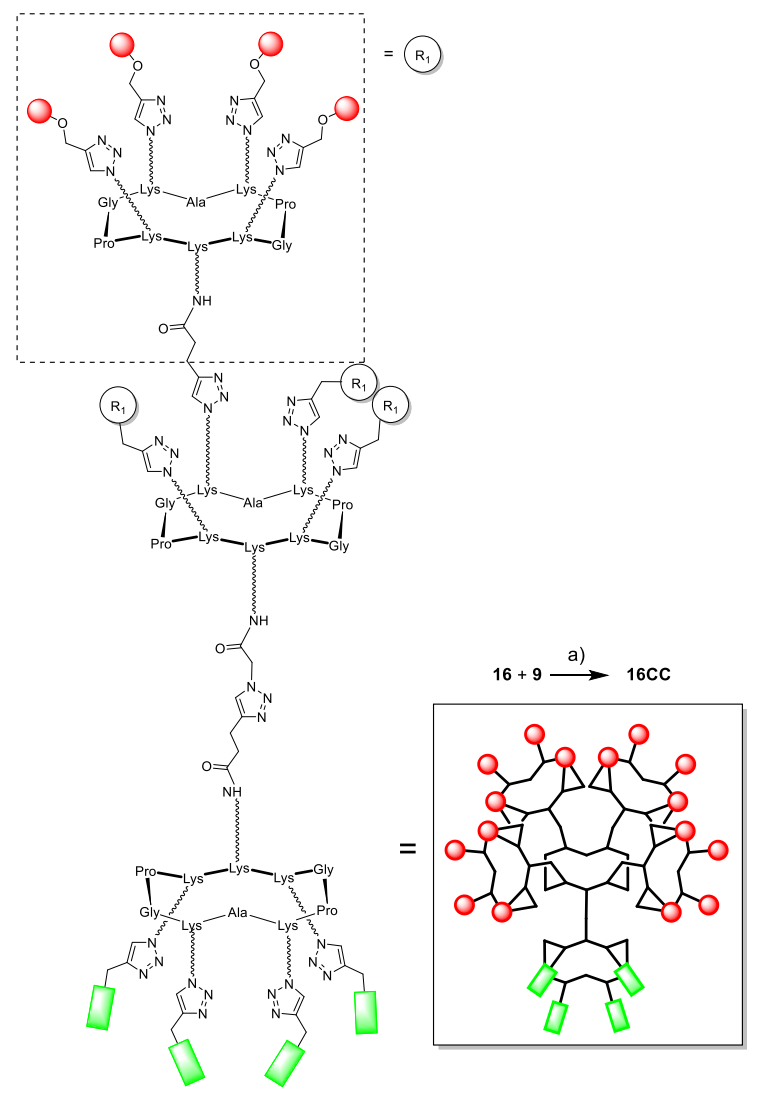

$R_{2}=$
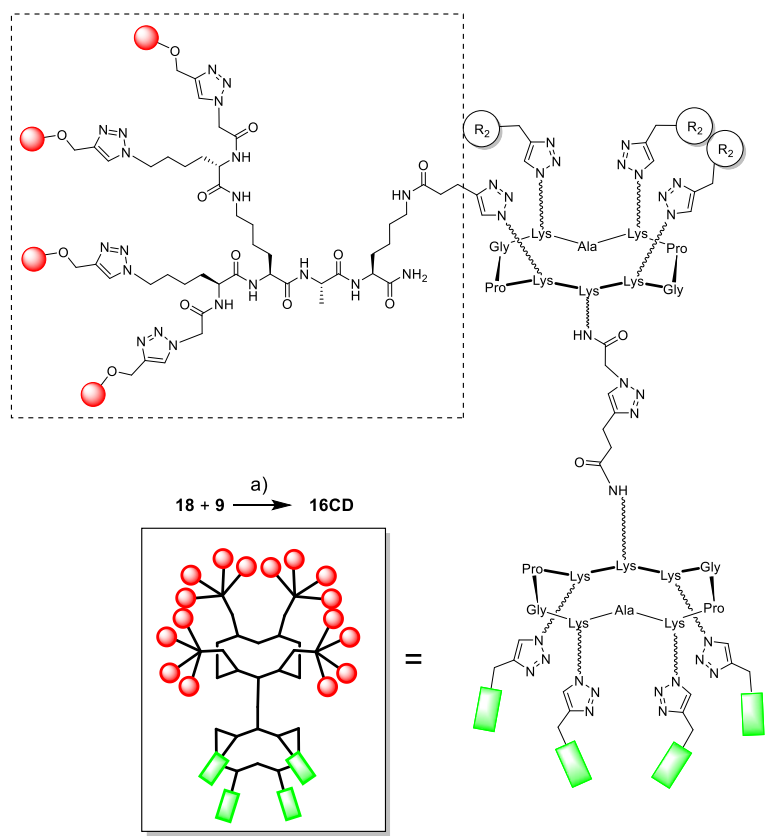

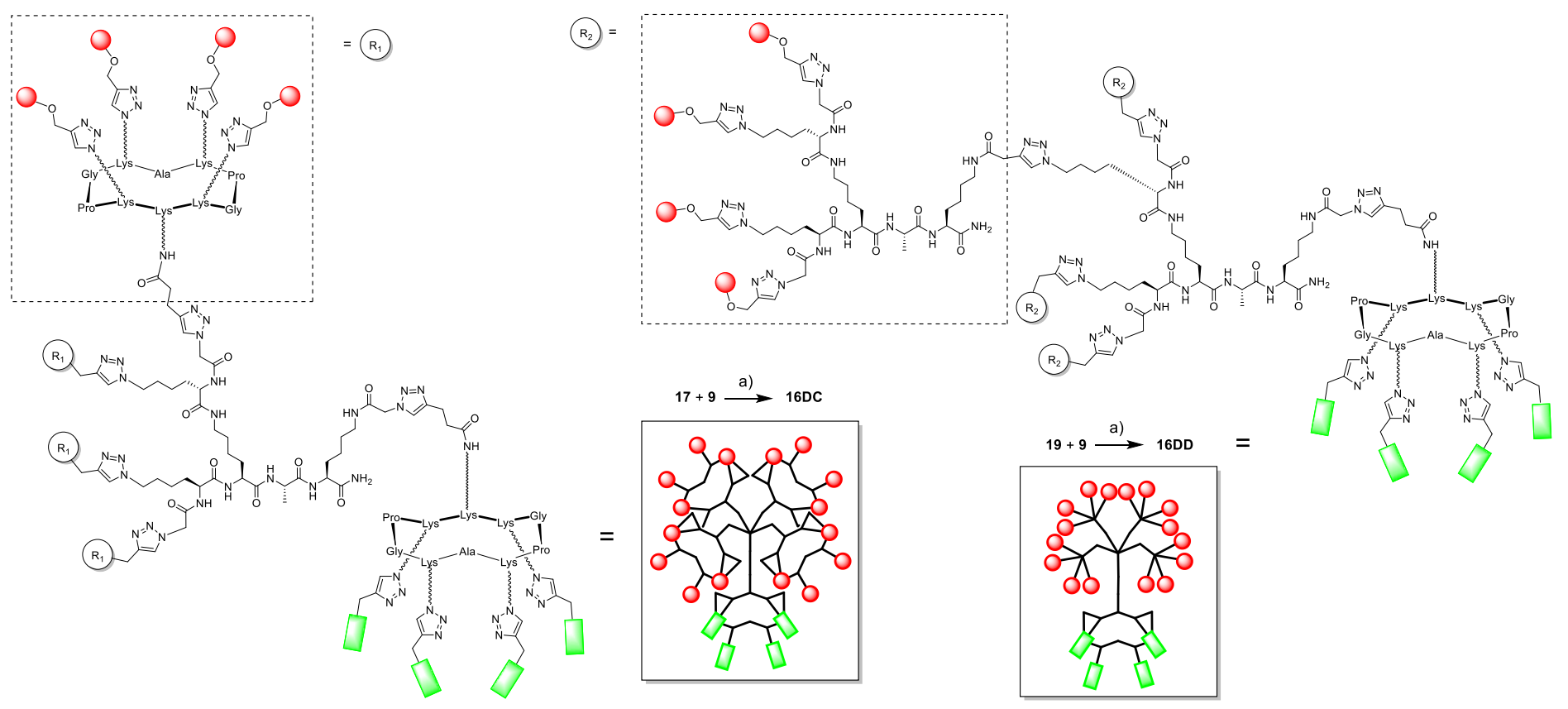



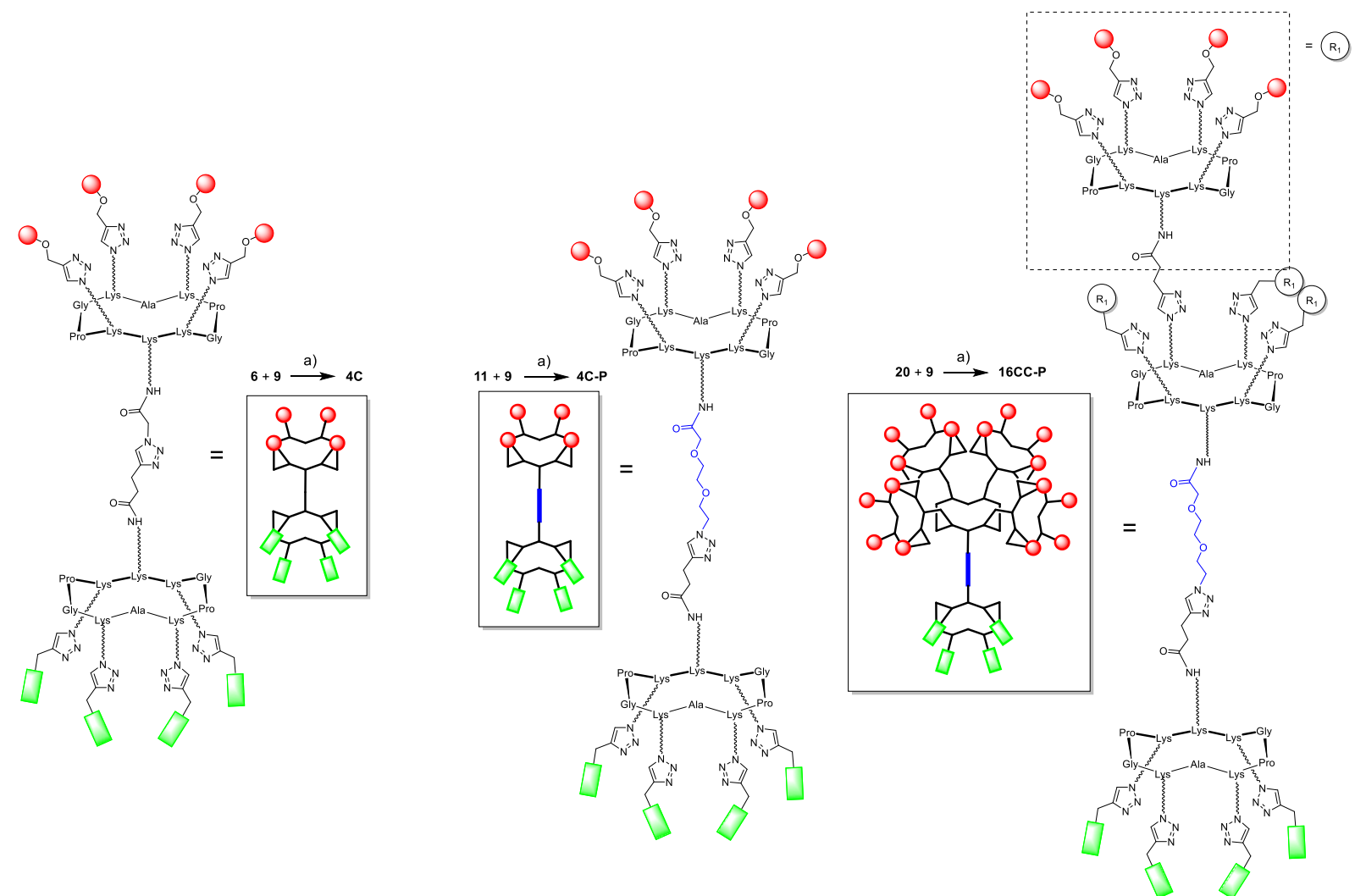

Scheme 3. Conjugation of ARGs. Reagents and conditions: a) $\mathrm{CuSO}_{4} \cdot 5 \mathrm{H}_{2} \mathrm{O}$, THPTA, Na ascorbate, DMF, PBS, rt, $2 \mathrm{~h}$.

\section{Biological evaluation of ARGs}

We first evaluated the influence of the ABM geometry in ARGs on the ternary complex formation between serum antibodies and M21 melanoma cells overexpressing $\alpha_{v} \beta_{3}$ integrins, then we studied whether this interacting complex is correlated to the immune cytotoxicity.

\section{Influence of the Rha display}

We previously observed by fluorescence-activated cell sorting (FACS) and confocal microscopy that optimal condition to detect the formation of the ternary complex with purified antibodies and M21 cells mainly depends on the ARG concentration..$^{22}$ On this basis, and because ARGs should ideally be used without preimmunization, commercial antibody or additional immune effector, the same conditions 
have been reproduced with serum as source of anti-Rha antibodies, which allowed to determine that IgM is the main class of interacting antibody with ARG. In the present work, we decided to study the binding potency of the new ARGs library with M21 as target cell and endogenous anti-Rha IgM in the conditions that have been previously determined.

Several binding experiments have been performed with M21 cells, human serum and ARGs. As previously reported, we first observed that the negative unglycosylated control (9) does not interact with human serum antibodies thus indicating that neither the peptide scaffold nor the triazole linkages induce unspecific binding with anti-Rha. We next determined that $100 \mathrm{nM}$ is indeed the optimal concentration of $16 \mathrm{CC}$ to form the ternary complex. We indeed observed a dose-response curve as a gaussian function which is typical with the simultaneous interaction of heterobifunctional ligands with two biological partners ${ }^{23}$ (Fig. S52 in ESI). In addition, significant differences have been observed between ARGs, which can be mainly attributed to the ABM geometry. As shown in Fig. 2, the architecture showing the best binding is composed of a central cyclopeptide core displaying Rha at the periphery of cyclopeptide branches (16CC). Interestingly, the utilization of branched dendron (16CD) disrupted the binding to IgM presumably due to the higher flexibility of the peptide framework. Confocal microscopy confirmed these results since significantly higher fluorescence was observed at M21 cell surface with ARG $16 \mathrm{CC}$ (Fig. 3). When the peptide dendrimer was used as the central core of ARGs (16DD and 16DC), low binding was also observed suggesting a weaker ability of these compounds to promote the ternary complex formation. 


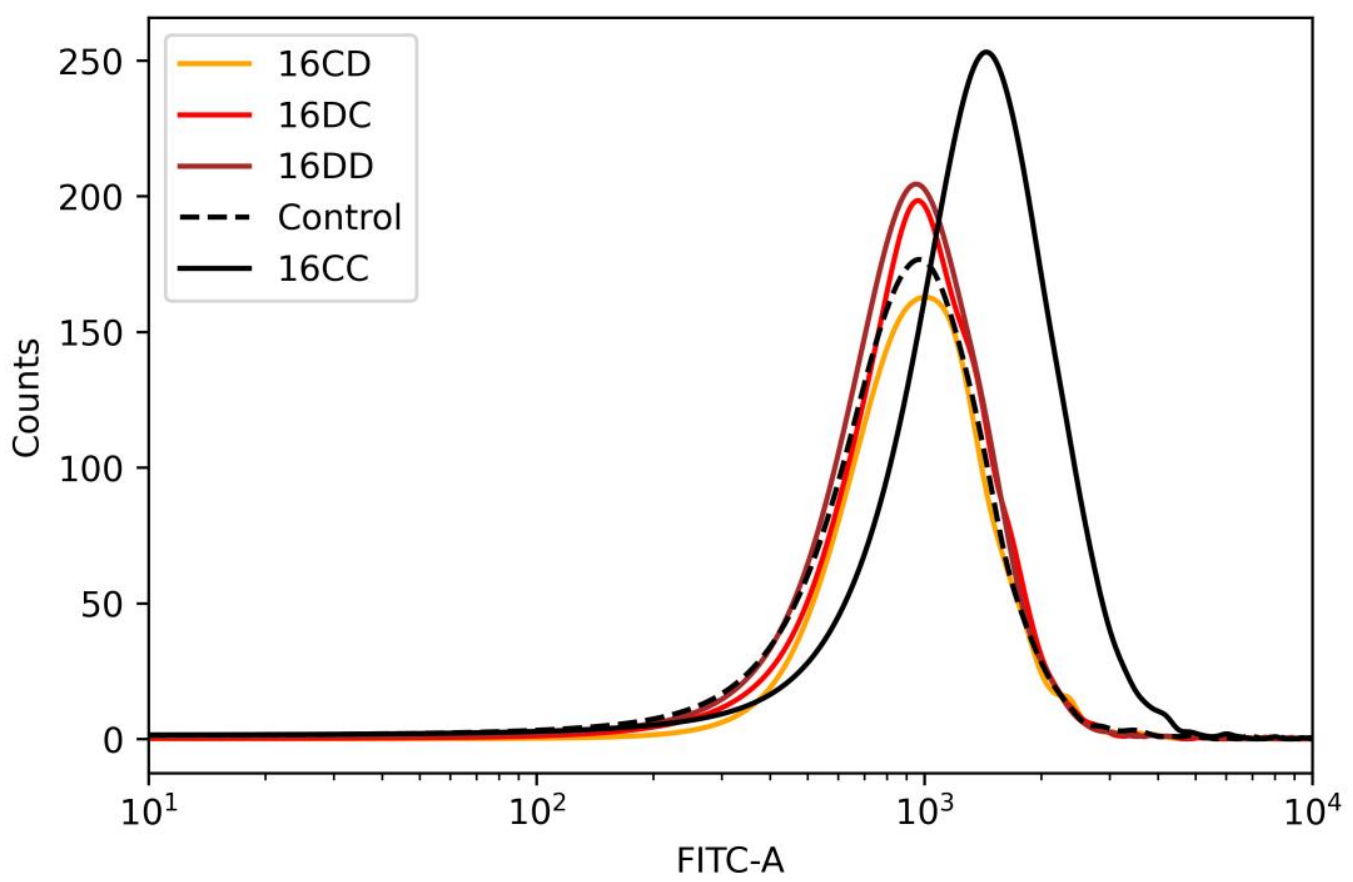

Fig. 2 Flow cytometry analysis of the recruitment by ARGs of anti-Rha IgM present in human serum on M21 cell surface (revelation with AlexaFluor488-coupled anti-human IgM antibody). Cells exposed to the unglycosylated compound (9) and human serum was used as control (black dotted line).
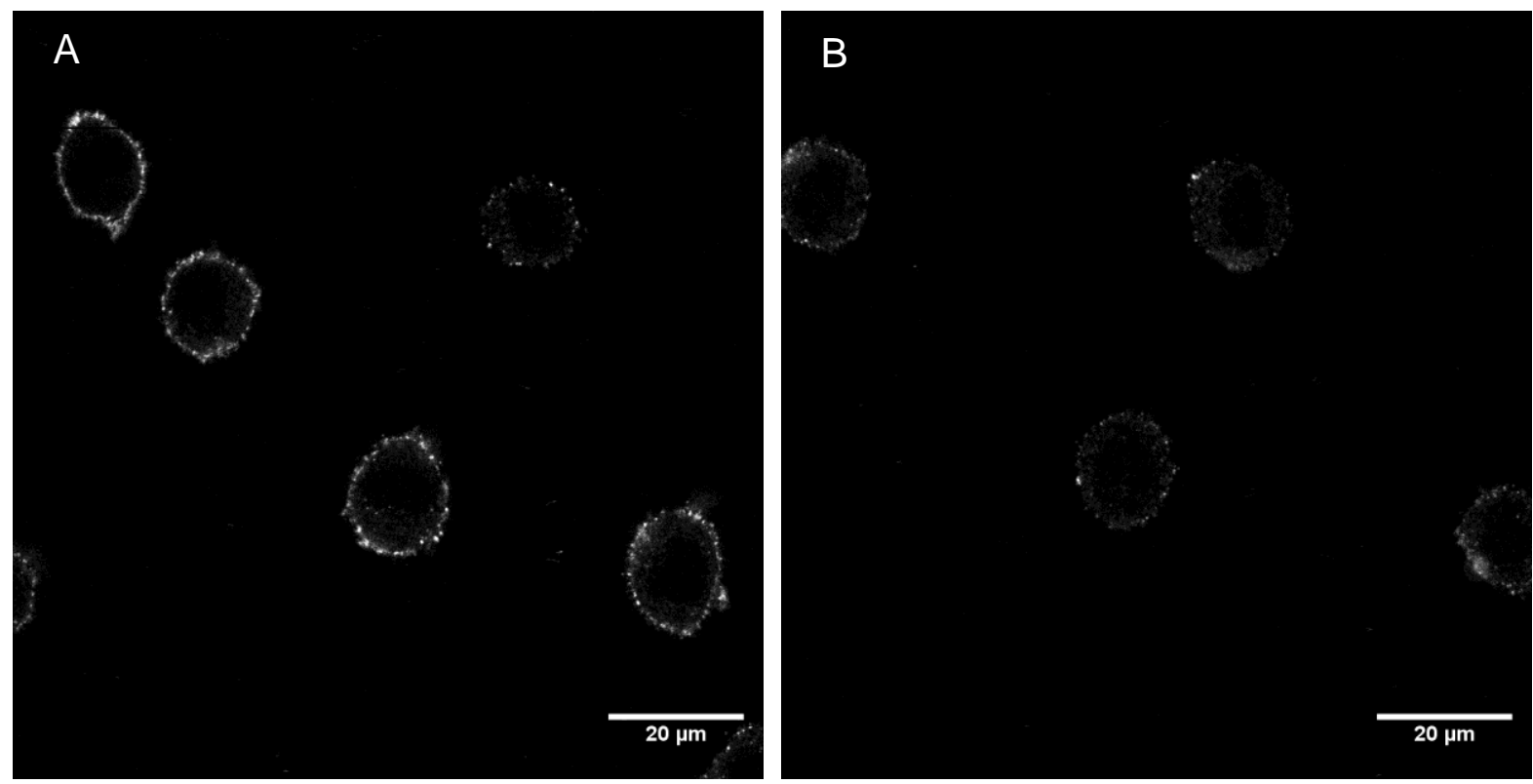

Fig. 3 Confocal microscopy images of M21 cells incubated with $100 \mathrm{nM}$ of ARGs 16CC (A) and 16CD (B) and human serum (50\%). Anti-Rha binding at the cell surface was revealed with AlexaFluor488coupled secondary anti-human IgM antibody.

The formation of the ternary complex is the crucial step to promote cytotoxicity against cancer cells which can occur following different immune mechanisms, in particular IgM-induced complement-dependent cytotoxicity. ${ }^{24}$ Thus, after having 
identified optimal ARGs for the binding to both M21 cells and natural IgM, we next performed cell viability assay ${ }^{25}$ to evaluate both the ability of $A R G$ to induce cytotoxicity and the correlation between the ARG architectures. This assay is based on the measurement of the fluorescence release when cytolysis occurs in the presence of ARG and serum. Intra-cellular labelling was first performed by the conversion of the membrane permeant (i.e. the non-fluorescent acetoxymethyl ester of BCECF $\left(2^{\prime}, 7^{\prime}\right.$ bis(carboxyethyl)-5,6-carboxyfluorescein) by esterases leading to the formation of a fluorescent dye in cytoplasm. The labelled cells were then incubated with ARG and human serum. If the ternary complex is formed, it presumably activates the complement cascade resulting in cytolysis, which can be visualized by fluorescence measurement.

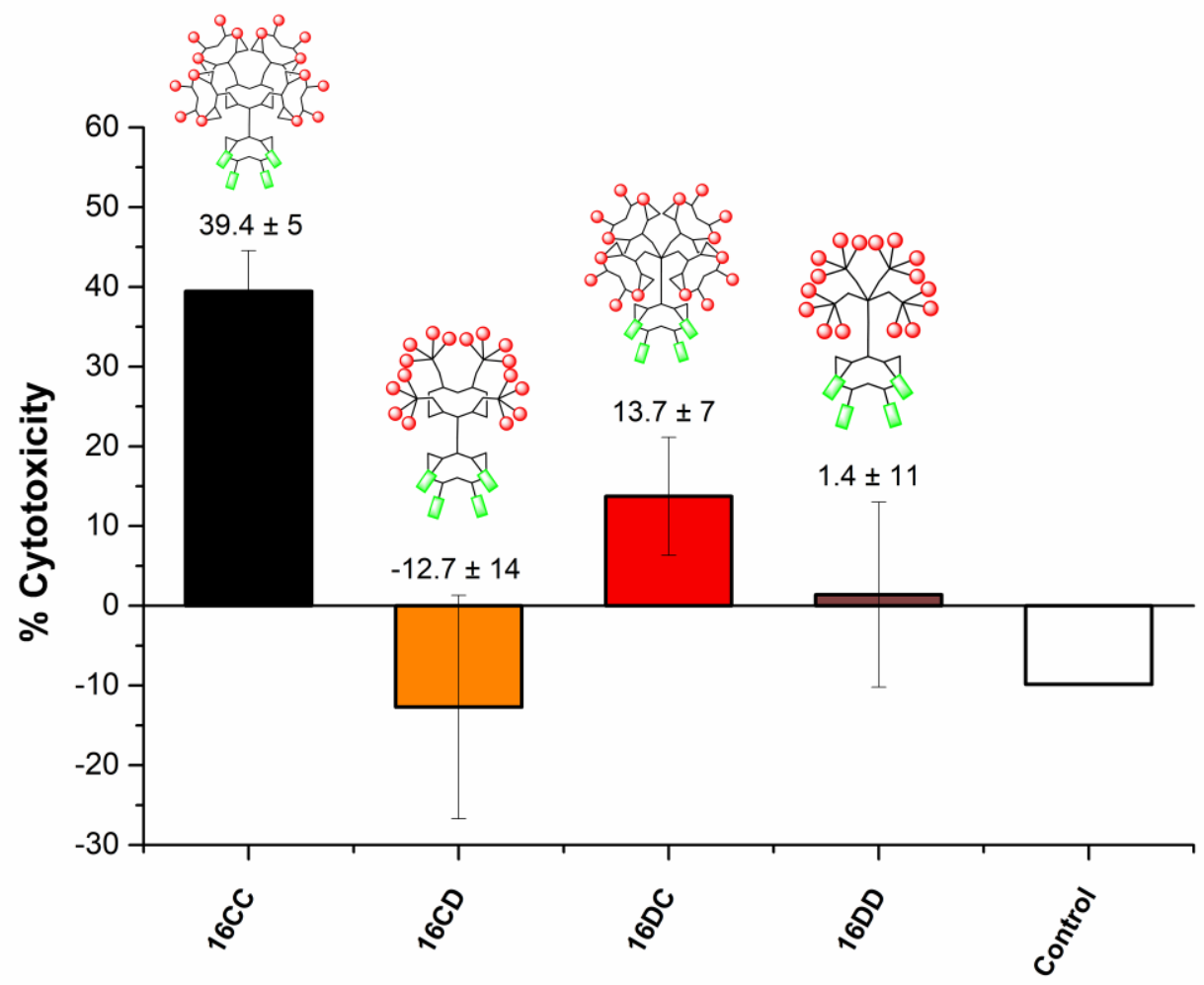

Fig. 4 Cytotoxicity induced by ARGs (100 nM) and human serum (50\%) towards M21 cells (average value of 4 successive experiments). Cells exposed to the unglycosylated compound (9) and human serum was used as control. 
This cell viability experiment clearly showed a high cytotoxic effect (up to $39.4 \pm 5 \%$ ) with $100 \mathrm{nM}$ of ARG $16 \mathrm{CC}$ which was previously identified by FACS as the best ligand. This observation clearly confirms its ability to recruit antibodies from serum and to induce a targeted immune response against M21 cells (Fig. 4). More interestingly, the same experiment was reproduced with different human serum to evaluate to ability of $16 \mathrm{CC}$ to be active for different population of donor. We indeed observed cytotoxicity related to cell exposure with ARG $16 \mathrm{CC}$ and with all $\mathrm{HS}$ with value going from 40 to $57 \%$ (Fig. S 53 in ESI). On the contrary, lower to negligible cytolysis was measured for ARG 16CD, 16DC and 16DD which were also identified as the worst ligand by FACS. These experiments therefore highlight the importance of the design of ARG to induce a potent immune response. Noteworthy, cytotoxic effects of up to $60 \%$ were reported by other groups using assays preformed after pre-immunization or by using purified antibodies and/or complement protein to improve the immunological response. In our experiment, we ruled out the addition of external immunological effector to focus on the effect of $A R G$ itself in the presence of human serum, instead of its combination with other external immune effectors. In these conditions, our results showed cytotoxicity at similar level than the best ARMs reported in the literature, thereby confirming the importance of the multivalent presentation of Rha and the potency of ARG to be used in antitumoral immunotherapy.

\section{Influence of the spacer length}

It was previously demonstrated that the distance between ABM and TBM may influence the immunological effect. ${ }^{26,27}$ We finally evaluated if the presence in ARGs of a PEGylated spacer between the two binding modules could improve the accessibility of both Rha and CRGD and facilitate the ternary complex formation (Fig. 
5). To do this, we performed the same experiments described previously with $\mathbf{4 C - P}$ and 16CC-P in comparison with their analogues with shorter spacer (4C and 16CC).

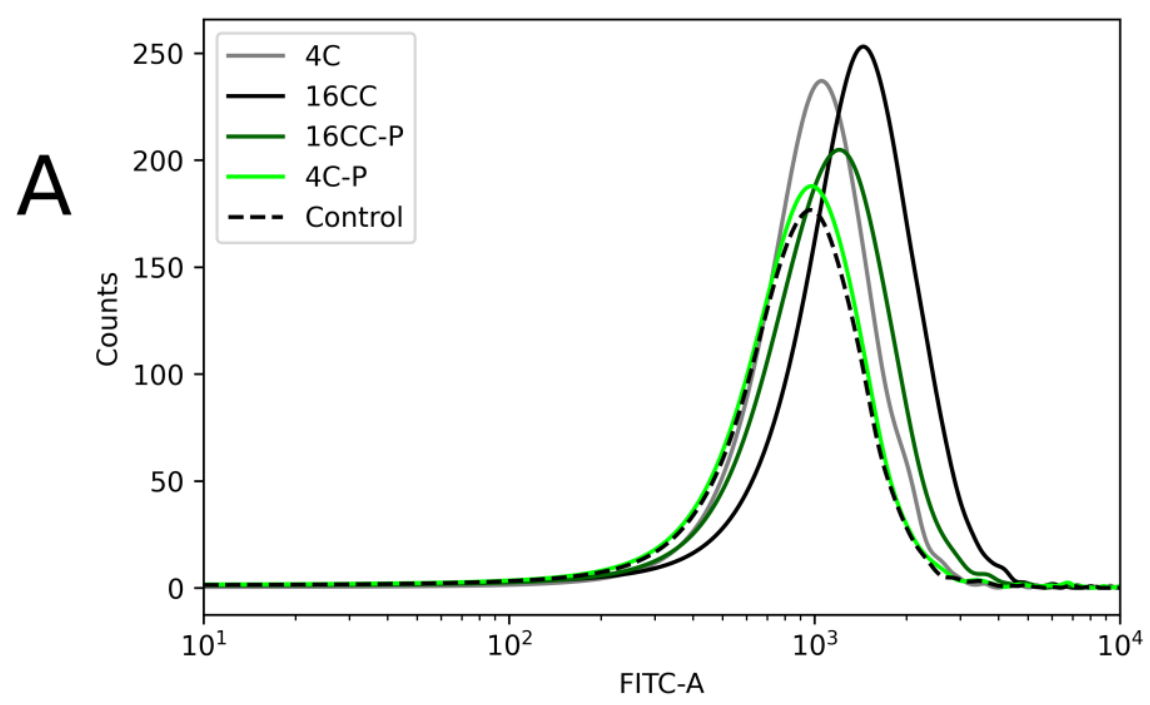

B

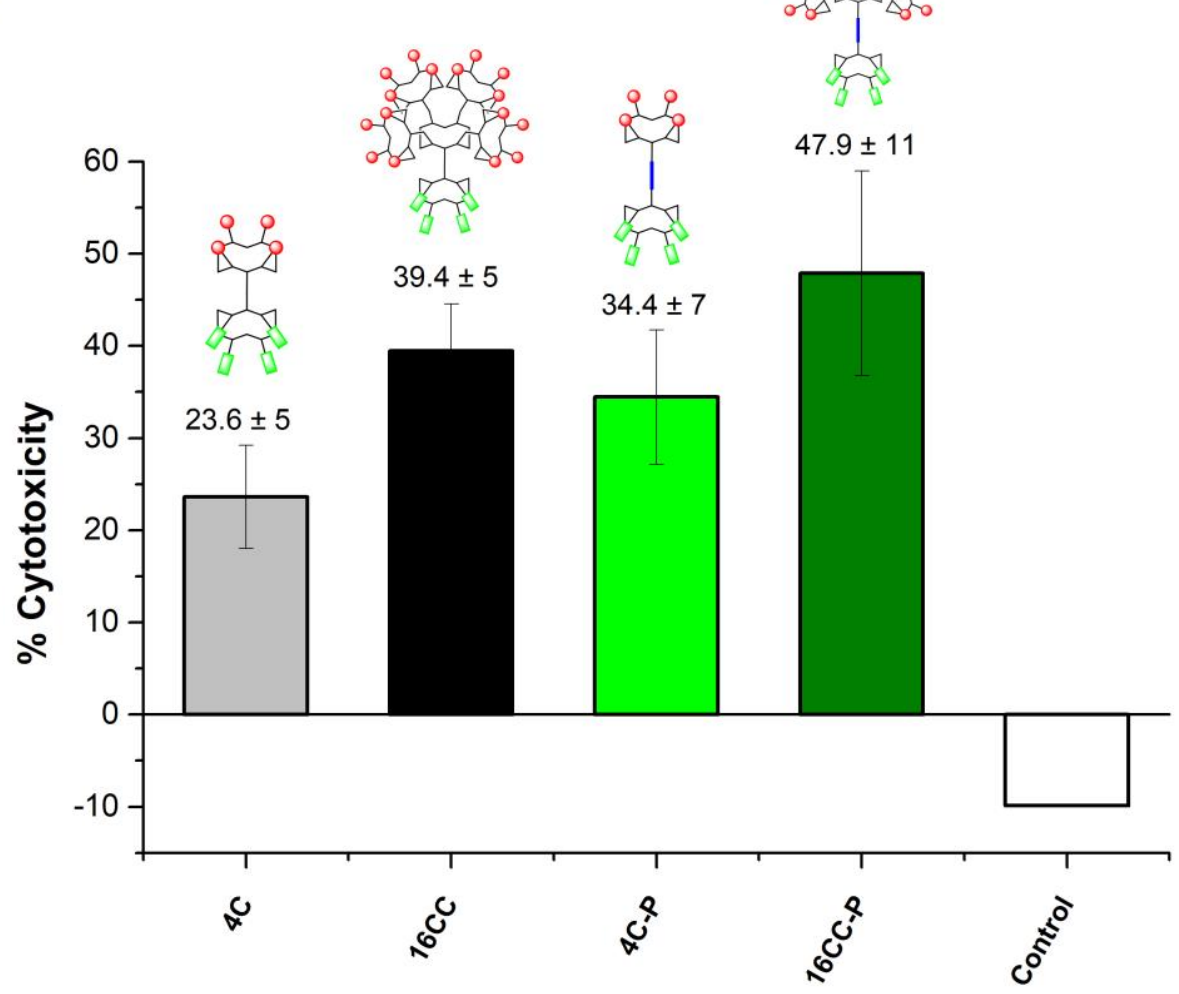

Fig. $5 \mathrm{~A} /$ Flow cytometry analysis of the recruitment by ARGs of anti-Rha IgM present in human serum on M21 cell surface (revelation with AlexaFluor488-coupled anti-human IgM antibody). B/ Cytotoxicity induced by ARGs (100 nM) and human serum (50\%) towards M21 cells (average value of 4 successive experiments). Cells exposed to the unglycosylated compound (9) and human serum was used as control in both assays. 
Interestingly, we first observed that both compounds $\mathbf{4 C}$ and $\mathbf{4 C}$-P with lower valency promote significant cytotoxic effect of $23.6 \%$ and $34.4 \%$ respectively (Fig. $5 B$ ), whereas no apparent ternary complex was detected by FACS (Fig. 5A). This observation might be explained by the lower avidity of ARGs displaying tetravalent rather than hexadecavalent $\mathrm{ABM}$ as found in $16 \mathrm{CC}$. Unlike cell viability assay, FACS binding experiment require successive washing steps which may dissociate low avidity interacting complexes, therefore precluding the observation of fluorescent signal at the cell surface. Interestingly, $16 \mathrm{CC}-\mathrm{P}$ presenting exactly the same ABM than $16 \mathrm{CC}$ revealed a slightly higher cytotoxic level towards M21 cells (47.9 and 39.4\%, respectively) while a lower fluorescent signal was detected by FACS. This difference could be attributed to the different format between both assays. By contrast with the viability assay, FACS requires a fluorescent secondary antibody to detect the formation of the ternary complex. The presence of a flexible PEGylated spacer could bend the ARG structure, thereby inducing a lower availability of the complex for the binding with the secondary antibody. It appears, however, that the spacer in both 4C-P and 16CCP leads to a significant increase in the cytotoxicity against M21 cells compared to their parent structures $4 \mathrm{C}$ and $16 \mathrm{CC}$. Additional studies would be needed to vary size and nature of the spacer to evaluate the effect of its rigidity and hydrophilicity to recruit higher titers of antibodies at the membrane cell surface.

\section{Cancer cell specificity}

To evaluate the cell specificity, the triple negative breast cancer cell line BT-54928 was used as negative cell line control. After having confirmed its low level of $\alpha_{v} \beta_{3}$ integrin expression as found in normal cells (Fig. S 54 in ESI), we first observed by 
FACS that ARG $16 C C$ does not recruit natural antibodies against the BT-549 (Fig. S 55 in ESI). We finally evaluated the potential unspecific cytotoxic effect for all ARGs towards BT-549. As expected, no significant cytotoxicity was observed under the conditions described above (Fig. S 56 in ESI). Altogether, these experiments clearly demonstrate that the antibody recruitment and the cytotoxicity are closely related to the level of integrin expression of the cancer cell line, thus suggesting that ARG $16 C C$ has the ability to selectively target cancer instead of normal cell.

\section{Conclusions}

We have reported Antibody Recruiting Glycodendrimers, displaying CRGD for the binding to melanoma cell line M21, linked with or without PEGylated spacerl to different rhamnosylated ABM varying in the geometry of the sugar unit. We observed by FACS and confocal microscopy that the ABM structure strongly influences the interaction between endogenous anti-Rha IgM, ARG and M21. ARG 16CC based on cyclopeptides indeed shows the higher binding to serum IgM, presumably due to more appropriate scaffold rigidity and Rha accessibility. More interestingly, we demonstrated that ARGs can induce cytotoxicity of cancer cell line expressing high level of integrin (M21) in the presence of human serum as the unique source of immunity effectors. Cell viability assays indeed showed strong cytotoxicity against M21 and not against BT-549, with a close correlation with the ABM structure. The 16CC ARG which was identified as the best IgM ligand was indeed tested with HS from different donors and has shown up to $57 \%$ of immune-mediated toxic effect against M21. Finally, we evaluated the influence of the spacer linking TBM and ABM. We observed a significant increase of cytotoxicity for ARG having a PEGylated linker 16CC-P (48\%) as well as with $\mathrm{ABM}$ of lower valency $\mathbf{4 C - P}$ ( $34 \%$ vs $23 \%$ for $\mathbf{4 C}$ ). Altogether, our results clearly 
demonstrate the influence of the ABM structure in immunological effect against cancer cell overexpressing $\alpha_{v} \beta_{3}$ integrins in presence of endogenous antibodies present in human bloodstream. This study clearly highlights critical structural parameters that have to be tuned for optimizing antitumoral effects and enabling immunotherapeutic perspective for cancer patients. Our lead compounds $16 \mathrm{CC}$ and 16CC-P are currently investigated in humanized mice models to evaluate their toxicity, stability, biodistribution and pharmacological properties in vivo.

\section{Acknowledgements}

This work was supported by CNRS, Université Grenoble Alpes, ICMG FR 2607, the French ANR project Glyco@Alps (ANR-15-IDEX-02), Labex ARCANE and CBHEUR-GS (ANR-17-EURE-0003). O.R. acknowledge the European Research Council Consolidator Grant “LEGO” (647938) for B.T., S. A., B. L., E. L., D.G and C.T and Proof of Concept Grant "THERA-LEGO” (963862). We thank Dr. J.-L. Coll (IAB, Grenoble) for providing M21 cell line and Cécile Cottet (LBFA, Grenoble) for confocal microscopy experiments and for giving access to flow cytometer.

\section{Notes and references}

1 P. Sharma, K. Wagner, J. D. Wolchok and J. P. Allison, Nat. Rev. Cancer, 2011, 11, 805-812.

2 S. Farkona, E. P. Diamandis and I. M. Blasutig, BMC Med., 2016, 14, 73.

3 R. S. Riley, C. H. June, R. Langer and M. J. Mitchell, Nat. Rev. Drug Discov., 2019, 18, 175-196.

$4 \quad$ D. A. Spiegel, Nat. Chem. Biol., 2010, 6, 871-872.

5 P. J. McEnaney, C. G. Parker, A. X. Zhang and D. A. Spiegel, ACS Chem. 
Biol., 2012, 7, 1139-1151.

6 P. J. McEnaney, C. G. Parker and A. X. Zhang, in Annual Reports in Medicinal Chemistry, 2017, pp. 481-518.

7 K. Sasaki, M. Harada, Y. Miyashita, H. Tagawa, A. Kishimura, T. Mori and Y. Katayama, Chem. Sci., 2020, 11, 3208-3214.

8 A. Uvyn and B. G. De Geest, ChemBioChem, 2020, 21, 3036-3043.

9 R. M. F. Tomás and M. I. Gibson, Biomacromolecules, 2019, 20, 2726-2736.

10 A. Uvyn, R. De Coen, O. De Wever, K. Deswarte, B. N. Lambrecht and B. G. De Geest, Chem. Commun., 2019, 55, 10952-10955.

11 J. Sianturi, Y. Manabe, H. Li, L. Chiu, T. Chang, K. Tokunaga, K. Kabayama, M. Tanemura, S. Takamatsu, E. Miyoshi, S. Hung and K. Fukase, Angew. Chem. Int. Ed., 2019, 58, 4526-4530.

12 B. Liet, E. Laigre, D. Goyard, B. Todaro, C. Tiertant, D. Boturyn, N. Berthet and O. Renaudet, Chem. - A Eur. J., 2019, 25, 15508-15515.

13 M. Mammen, S.-K. Choi and G. M. Whitesides, Angew. Chem. Int. Ed., 1998, 37, 2754-2794.

14 J. J. Lundquist and E. J. Toone, Chem. Rev., 2002, 102, 555-578.

15 L. L. Kiessling, J. E. Gestwicki and L. E. Strong, Angew. Chem. Int. Ed., 2006, 45, 2348-2368.

16 O. Oyelaran, L. M. McShane, L. Dodd and J. C. Gildersleeve, J. Proteome Res., 2009, 8, 4301-4310.

17 M. E. Huflejt, M. Vuskovic, D. Vasiliu, H. Xu, P. Obukhova, N. Shilova, A. Tuzikov, O. Galanina, B. Arun, K. Lu and N. Bovin, Mol. Immunol., 2009, 46, 3037-3049.

18 I. Bossu, M. Šulc, K. Kenek, E. Dufour, J. Garcia, N. Berthet, P. Dumy, V. Křen 
and O. Renaudet, Org. Biomol. Chem., 2011, 9, 1948-1959.

19 N. Berthet, B. Thomas, I. Bossu, E. Dufour, E. Gillon, J. Garcia, N. Spinelli, A. Imberty, P. Dumy and O. Renaudet, Bioconjugate Chem., 2013, 24, 15981611.

20 C. Pifferi, B. Thomas, D. Goyard, N. Berthet and O. Renaudet, Chem. Eur. J., 2017, 23, 16283-16296.

21 C. Pifferi, A. Ruiz-De-Angulo, D. Goyard, C. Tiertant, N. Sacristán, D. Barriales, N. Berthet, J. Anguita, O. Renaudet and A. Fernández-Tejada, Chem. Sci., $2020,11,4488-4498$.

22 E. F. Douglass, C. J. Miller, G. Sparer, H. Shapiro and D. A. Spiegel, J. Am. Chem. Soc., 2013, 135, 6092-6099.

23 B. Han, J. Biol. Chem., 2020, 295, 15280-15291.

24 D. Hendriks, G. Choi, M. de Bruyn, V. R. Wiersma and E. Bremer, in International review of cell and molecular biology, 2017, vol. 331, pp. 289-383.

25 M. A. Kolber, R. R. Quinones, R. E. Gress and P. A. Henkert, J. Immunol. Methods, 1988, 108, 255-264.

26 A. X. Zhang, R. P. Murelli, C. Barinka, J. Michel, A. Cocleaza, W. L. Jorgensen, J. Lubkowski and D. A. Spiegel, J. Am. Chem. Soc., 2010, 132, 12711-12716.

27 A. F. Rullo, K. J. Fitzgerald, V. Muthusamy, M. Liu, C. Yuan, M. Huang, M. Kim, A. E. Cho and D. A. Spiegel, Angew. Chem. Int. Ed., 2016, 55, 3642-3646.

28 R. M. Neve, K. Chin, J. Fridlyand, J. Yeh, F. L. Baehner, T. Fevr, L. Clark, N. Bayani, J.-P. Coppe, F. Tong, T. Speed, P. T. Spellman, S. DeVries, A. Lapuk, N. J. Wang, W.-L. Kuo, J. L. Stilwell, D. Pinkel, D. G. Albertson, F. M. Waldman, F. McCormick, R. B. Dickson, M. D. Johnson, M. Lippman, S. Ethier, A. Gazdar and J. W. Gray, Cancer Cell, 2006, 10, 515-527. 
